\title{
Identity formation: professional development in practice strengthens a sense of self
}

\begin{abstract}
This paper explores how practitioners in a hostile context make sense of continuing professional development (CPD). Critics worldwide question the professional status of human resources seeing the function as an underdog to well-established professions. The study uses an interpretivist approach to examine the conceptual interweaving of learning and identity development. Findings reveal that continuing development expands knowledge capabilities which affirm professional identity coherence. Professionalisation of the human resources field matters for the effective staff management of diverse multicultural workforces. This suggests a need for CPD providers to support practitioners better articulate and critically demonstrate the significance of sourcing, coordinating and retaining global talent. To counter pejorative views, practitioners base cumulative improvements in people management skills to a claim for renewed respect. This robust approach provides a resilient pathway for other occupational groups who aspire to professional status.
\end{abstract}

Keywords: identity; continuing professional development; professionalism; human resources; practitioners

\section{Introduction}

Practitioners are expected to engage in continuous professional development (CPD); an expectation framed by professional regulation and knowledge competence that underpins expert status (Boud and Hager 2012; Fenwick 2008). The economic and societal benefits of continuing professional development are apparent in scale: in the USA $£ 20$ billion is spent annually on continuing professional education and in the UK 3.41 million practitioners invest in professional development (OECD 2010; Friedman and Afitska 2009). The premise of this paper is that the strategic value attributed to professional development also needs to include the significance of identity construction in recent occupational groups.

This study examines continuing development from the singular position of human resource (HR) practitioners seen as organisational underdogs in professional acceptance. The research is structured around three questions: (i) How do human resource specialists perceive development? (ii) How is professional development conceptualised? And (iii) What is the relevance of CPD to the HR role? Findings suggest that continuing development represents a professional value for HR specialists; an important signal of growing knowledge competence. This paper adds to the international literature in providing situated evidence of how practitioners contend in the face of harsh criticism and proactively link ongoing skill development to bolster claims for professional respect.

Despite the proclaimed benefits of professional development and education (Volles 2014), there is scant research on the theoretical underpinnings of CPD. The literature on professional learning spotlights applied practice in medical and educational fields but neglects theoretical conceptualisations. Two pertinent calls seek deeper insight into continuing professional development: first, Kennedy $(2014,2)$ asserts that the 'why' of CPD needs to be given as much attention as the 'how' in debate. Second, Friedman and Afitska (2009) call for research which encourages fresh thinking on how individuals navigate 
professional development in practice. This study addresses these calls to focus on a specific occupational group, human resources, who internationally face hostile critics across industry and academia (Hammond 2005; Sheehan and DeCieri 2012). The complex characteristics of the HR function and conflicting stakeholder expectations make this group of particular interest to researchers investigating professional learning. This paper reveals that HR specialists' under public scrutiny endeavour to demonstrate practice capability that influences a sense of identity.

Within this paper CPD is defined as learning that is pertinent to the workplace, directly affects job role, continuity and professional status (Mulvey 2013; Volles 2014). The article begins with a literature review of diverse expectations of professional development. Then professional learning is situated in a theoretical framework of identity development. A reflexive hermeneutic methodology uses a purposive approach to explore understandings of professional development in context. The data analysis examines how interpretations of CPD shape perceptions of human resource identity in practice. The paper discusses the signal value of professionalism for practitioners, and concludes with the research implications for theory and practice.

\section{Professional development - open to interpretation}

The rhetoric of continuous development advocates work-related learning to expand individual capabilities, enhance human capital value and boost economic productivity (OECD 2010). Stiglitz $(1999,308)$ notes: 'knowledge is central to successful development', and this concept of learning as a global public good, frames a broad understanding of continuous development. Definitions of CPD are diffuse in the literature with overlapping principles of lifelong learning, professional education, personal development, career advancement and workplace learning (see Boud and Hager 2012; Eraut 2004; Kennedy 2014). Hence, CPD resembles an umbrella construct promoted as a universal 'good thing'; good for the individual, the organisation, and society. But broad interpretations mask the theoretical ambiguity of professional learning and divergent definitions create employment tensions (Trede, Macklin and Bridges 2012; Mackay 2015). Roessger $(2013,18)$ states CPD is widely interpreted as: 'professional performance, income generation, public relations strategy and learner self-actualisation'. Noting these differences Friedman and Phillips $(2004,364)$ argue:

If there is little agreement on the objectives of CPD or the steps needed to achieve them, or if CPD programmes try to encompass conflicting objectives, it seems likely that individual professionals will be unclear as to why they should participate in CPD.

Practitioner understandings in specific contexts therefore merit investigation. Evans (2008) argues that CPD is subjective and open to interpretation by a range of stakeholders; including professional bodies, managers, clients, students and the media. Organisational interests in employee ability to adapt to changing work circumstances (OECD 2010) stem from the pressures of globalisation, rising retirement ages, and longer working lives (Volles 2014). Accordingly, research to enhance understandings of practitioner development in context is of strategic interest to educators, employers, institutions and society in extending employment flexibility.

Professional development supports employee autonomy and Fenwick, Nerland and Jensen $(2012,5)$ assert that professional education invariably reflects: 'an individualist, subject-centric, psychological conception of knowledge and practice'. For example, individuals may guard knowledge of innovative work techniques for personal advantage. Yet Billett (2008) disagrees with presumptions of individual agency in work practice, contending that group interactions advance knowledge competence and promote technical development. 
Supporting this view of collective learning, Boud and Hager (2012) report that social relationships affect learning through workplace tips, informal discussions and ongoing reviews. The dynamic nature of continuing development highlights the effect of specific work contexts where no meaningful separation between learning and practice exists. Consequently, Cervero (2001) states only professional education delivers tangible evidence of development; while Kennedy (2014) acknowledges tensions between theory and practice when CPD is used for performance accountability.

In the specific case of human resources, the UK professional body requires evidence of continuing development: 'it is essential to demonstrate how you make an impact in the workplace' (www.cipd.co.uk). Such evidence is based predominantly on learning reflections of development experience (Mackay and Tymon 2013) but practitioners may struggle to show development from accumulating experience. The perception of the HR function as an organisational guardian of learning complicates expectations with Holden explaining the responsibility as: 'human resource development specialists are the natural gatekeepers of CPD' $(2012,2)$. Certainly the HR function analyses workforce development needs through performance reviews; a growing role in organisational measures to utilise CPD records as a benchmark of employee performance (Rothwell 2005; Gold et al. 2013). Such diverse expectations of professional development may baffle practitioners, and resonate with Roessger's $(2013,15)$ plea for greater clarity 'to secure the continued success of the field of CPD'.

\section{Human resources function struggles for professional respect}

The HR function struggles for recognition of knowledge legitimacy accorded to wellestablished professions, such as law. Critics worldwide point to loosely defined practice boundaries as people management is based on a common body of knowledge and shares jurisdiction with line managers (Farndale and Brewster 2005). An academic label of 'semiprofession' underlines HR's disputed claim to professional legitimacy (Gold et al. 2013; Freidson 2001); hence the function is regarded as an underdog to established professions. Critics denigrate human resources on two counts: 1) a deficient quality of competent practitioners, and 2) a failure to operate within a strategic partnership role. For instance, Kearns (2009) exclaims: 'we've allowed charlatans to come into it [HR], anybody can enter our profession' without qualifications. Similarly, in a provocative USA article titled: 'Why people hate HR', Hammond (2005) documents widespread criticism of failure to take strategic responsibility for producing people results. Further, research in Australia highlights global business pressures for talent management that increase expectations of practitioner capability (Sheehan and De Cieri 2012). Consequently, HR practice is a challenging proposition in a hostile environment.

Research calls for international respect for HR professionals and better appreciation of their pivotal role in sourcing, managing and retaining talent in globally competitive markets (Farndale, Scullion and Sparrow 2010, 166). But the struggle for professional respect continues despite Ulrich and Brockbank's (2005) authoritative assertion that introducing core competencies would transform legitimacy of the field. To uphold professional standing the American Society for Human Resource Management launched an educational curriculum designed to confer professional identity (SHRM 2007). Professional associations have a vested interest in brandishing members' credentials as a training academy (Cervero 2001) which increase demand for educational programmes. Arguably, this curriculum persuades HR practitioners to regard professional development as an occupational value. To counter criticism, HR specialists may seek to emphasise knowledge currency that flows from practice development. 


\section{Continuing development as a professional value}

Professional standards are prominent in regulatory frameworks across business disciplines with professional development central to behaviour (Edwards and Nicoll 2006). According to Mulvey the need to live up to professional standards, and sustain public trust, accentuates expectations of practitioner development:

'it is likely that the demand for CPD to be undertaken (and to be recorded) will only increase'.

$(2013,268)$

Professionalism is seen as central to occupational identity (Evetts 2003) as the construct defines individual attitudes and behavioural orientation. Freidson (2001) defines a traditional profession as distinguished by knowledge, skill and commitment to a set of beliefs and values. This seminal work on professionalism marks an ideological shift away from a checklist of behaviours towards an emphasis on professional values and ethics. CPD represents 'good practice' (Gold et al. 2013); a professional ideology of good intentions translated into actions. For academic staff CPD may sit on the margins of higher education (Becher 1999) of more relevance to pedagogic practice than academic scholarship; ambivalence to CPD may demonstrate resistance to a market-dominated discourse of managerial concerns. Nonetheless, Nixon $(2001,179)$ asserts that a moral base for professionalism is: 'the freedom of all, academics included, to learn and go on learning'. This exposes a tension between individual belief in integrity of good practice and market demands for assurance of trustworthiness.

What differentiates the context of human resource specialists is the vocal disparagement of professional legitimacy. Such a beleaguered practice situation may affect practitioner views of professional behaviour. Nevertheless, Sheehan and De Cieri $(2012,164)$ suggest globalisation has created new corporate roles for the HR function in 'the management of a geographically dispersed workforce', and the HR role can span institutional boundaries as policy enforcer, employee advisor and managerial champion. There is tension in diverse and often contradictory stakeholder interests. Although Trede et al. (2012) assert the complexity of identity development referring to learners' active participation, professional education is crucial to expand business knowledge and credibility as an expert. A key aspect of professional identity formation is then learning to effectively demonstrate and communicate the value of HR across organisations.

To summarise, practitioners face critics who question HR's claim to professional standing (Hammond 2005). The emerging question is whether such criticism affects practitioner views of professional development. Do expectations of human resources as organisational 'guardians of culture' (Farndale et al. 2010) influence professional development activity? In developing a professional identity individuals interpret the norms and behaviour of the community (Pratt et al. 2006). Indeed, prevailing organisational cultures can increase or diminish respect for human resources, which will affect learning opportunities and development interactions (Wenger and Snyder 2000). Two main issues emerge from the literature reviewed; first, diverse definitions of the purpose of professional development may affect practitioner interpretations, and second, international criticisms that marginalise the HR function may shape perceptions of the relevance of professional development. This article now moves to explain the research design used to explore sense-making of professional development with a purposive sample of HR practitioners and educators.

\section{The research study}

The research design is structured as an inductive approach to practitioner experiences of professional development. The selection of a phenomenological dimension privileges a 
subjective view of reality; exploring participants' lived experience and meanings in context (Saunders, Lewis and Thornhill 2011). An exploratory approach acknowledges that occupational identity is individually formed and socially constructed in changing situations. To this end, qualitative data seek multilayered views of professional development to inform a richer understanding of practice. Professional development experiences are built incrementally through a complex process of situated experiences and everyday learning (Billett 2008). Hesse-Biber $(2010,455)$ asserts that qualitative approaches 'seek to empower individuals' stories to understand how they make meaning within their social world'. Thus, in a sequential design the research involved interviews and survey data to interrogate theoretical perspectives of professional development, and consider the connections between learning development and identity formation (Freidson 2001; Alvesson 2010).

\section{Method}

The study's context

A public context of harsh critics who denigrate the HR function as a quasi-profession (Gold et al. 2013) justifies an investigation of working practitioner views. A literature emphasis on self-agency complements the investigation of a subjective, individual view of development (Mackay 2015). Roessger $(2013,17)$ argues researchers of CPD should conduct: 'Empirical designs in small-scale, controlled settings [...] to explore how social, affective and perceptional variables influence knowledge'. This validates an in-depth qualitative study of HR practitioners' interpretations of CPD behaviour. A purposive sampling technique (Tracy 2010) examines the self as the major unit of analysis in considering the research questions. Specifically, what does CPD mean to HR practitioners?

\section{Participants}

The study participants shared a higher education setting for exploring perspectives on professional development in two strands: (i) educators who specialise in human resource knowledge development and (ii) practitioners studying for an advanced-level professional accredited qualification. This purposive sample consisted of 18 human resources academics and 42 HR managers, advisors and business partners. To ensure survey design comparability, participants were selected on the following basis: employed in a human resources role; belonged to a relevant professional association and worked in an organisation with a policy of CPD.

\section{Interviews, survey and data analysis}

The research design drew on the notion of professional development as knowledge competence and skills currency. In collecting data, the researcher used open questions to allow for alternative conceptualisations of self-development without imposing an a priori framework of identity focus. Cunliffe $(2010,5)$ sees qualitative research as a craft: 'being careful about how we notice, bring to attention, and shape knowledge about organisational life'. Therefore in crafting the research study, the first phase consisted of 18 semi-structured interviews using a guideline protocol following a pilot study. The 13 female and 5 male educators interviewed all ranged in industry practice experience from 3 to 20 years, and taught full-time in a UK business school. Interviews were audio-recorded with consent, and lasted between 50-75 minutes at a convenient time and place for participants. To safeguard anonymity details, such as names, were removed from all transcripts. HR educators were asked about specific aspects of professional development: types of development activity, workplace expectations, motivations, and the relevance of continuing professional development to human resources.

The second phase was a survey of HR practitioners from diverse industry sectors, such as healthcare, manufacturing, defence systems, retail and local government. Participants 
were invited to complete a questionnaire and 42 volunteers responded. The survey consisted of ten statements which followed the interview protocol. For each statement about aspects of CPD, participants were asked to respond using a Likert scale from 1 to 5 ( 1 =strongly agree to $5=$ strongly disagree). Table 1 presents illustrative frequencies of response for four of the survey statements.

Table 1. Example of survey responses

\begin{tabular}{|c|c|c|c|c|c|c|}
\hline Item & Statement & $\begin{array}{l}\text { Strongly } \\
\text { Agree }\end{array}$ & Agree & Neither & Disagree & $\begin{array}{l}\text { Strongly } \\
\text { Disagree }\end{array}$ \\
\hline 2 & $\begin{array}{l}\text { Ongoing development is an essential part of } \\
\text { being a true professional. }\end{array}$ & 21 & 19 & 2 & - & - \\
\hline 4 & $\begin{array}{l}\text { Reading, informal conversations, and on-the } \\
\text { job practice is what matters in CPD. }\end{array}$ & 4 & 16 & 20 & 2 & - \\
\hline 5 & $\begin{array}{l}\text { HR practitioners are naturally committed to } \\
\text { continuous development and learning }\end{array}$ & 19 & 16 & 2 & 4 & 0 \\
\hline 8 & $\begin{array}{l}\text { A commitment to continuous development } \\
\text { does not bring any specific reward. }\end{array}$ & - & 8 & 6 & 26 & 2 \\
\hline
\end{tabular}

Then additional open questions invited participants to supplement their responses with freewriting comments to allow for diverse interpretations. Questionnaire responses were anonymised, and confidentiality remained at the forefront in the research design, data collection and subsequent analysis.

The coding as delineated by Weston et al., (2001) followed a three stage process: reading and re-reading the collected data, identifying descriptive codes, and then recognising pattern associations to develop interconnected themes that categorised responses. Although this implies a linear process, the analysis was iterative, circling back across transcripts and survey responses, to integrate descriptive codes. The seven coding sub-categories included: competence, agency, being professional; commitment to values; external pressure; workplace environment and internalised. This supported a systematic analysis of the interplay of educators and practitioners' views comparing the nuanced detail with holistic conceptions of CPD. To consider thematic interpretation (Cunliffe 2010), a visual mapping of the codes teased out patterns and interpretive insights of professional development which reflect a complex social reality. The researcher acknowledges partial overlap may occur across categories even when a systematic process intended cohesive quality of coding (Tracy 2010) to examine in-depth conceptions of professional development.

After coding the data were sorted thematically through the frame of the research questions; namely, how practitioners make sense of CPD, how they conceptualise professional development and what is the perceived relevance of professional learning to practice. Figure I presents an overview of the data coding sub-categories and main themes.

Figure I. Coding sub-categories and major themes 


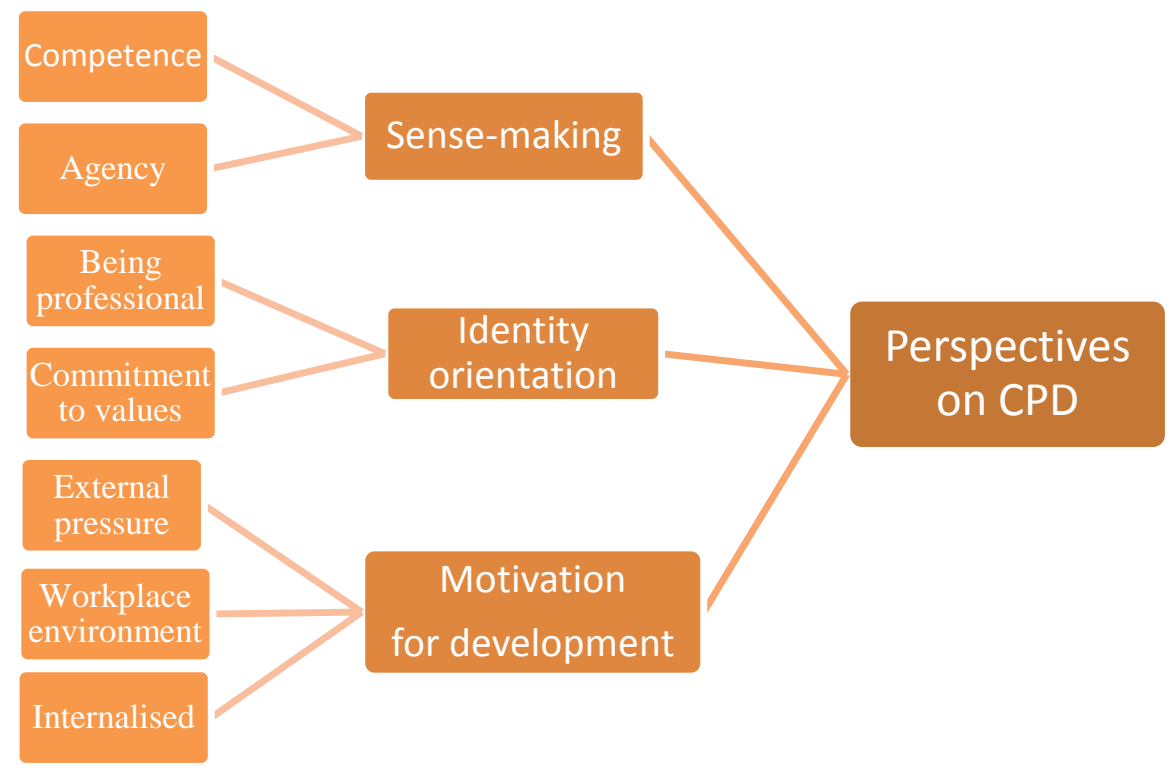

The data analysis is framed by Cunliffe's $(2010,12)$ approach to a reflexive hermeneutic interpretation of individual perspectives and workplace contexts. As discussed, participants' situated experience matters as the subjective, interactional nature of development influences occupational professionalism.

\section{Limitations}

A research limitation is the challenge of self-reported accounts; participants may project a positive image of development activity, or disregard informal everyday learning (Eraut 2004). Individuals may seek to emphasise social relations with the HR community that legitimates their own professional development. Furthermore, study participants were familiar with development reviews as a customary HR performance process; this ease with evaluations of learning progress does not necessarily apply to other disciplines. Previous surveys sponsored through membership of the UK professional body (Rothwell 2005) may have affected formal responses in contrast, this research is independent of professional association constraints. Although qualitative research does not afford generisability (HesseBiber 2010), this study provides rich insights into practitioner views of professional learning and efforts to counter criticisms that are echoed worldwide in a harsh practice environment (Farndale and Brewster 2005).

\section{Findings}

This section presents the three main themes emerging from the data of surveys, free writing responses and interview accounts of professional development. These complementary data sources paint a fuller picture of professional development in practice according to the major themes: sense-making, identity orientation and motivation for development.

\section{Sense-making of CPD}


CPD activity was seen to have two main purposes; to update knowledge competence and expand expertise. Participants emphasised the need for knowledge currency in proactively improving business acumen:

An example of my development learning is my volunteering to improve the HR information spreadsheets utilised by the department; I am proficient in IT and used this to my advantage to streamline the process for recording disciplinary and grievance information. [Practitioner]

More than half linked this need to the continuous scrutiny of human resources:

It is important in HR to continue professional development in the workplace to ensure your knowledge is up-to-date, as this enhances your credibility [Practitioner]

Strikingly, most respondents felt that development increases job performance (item 6), despite limited evidence of causality. This can be attributed to intrinsic benefits experienced (item 8) including learning enjoyment, confidence and self-achievement. As the survey was voluntary, those who responded may incline to a positive view of development. Individualised understandings of CPD practice ranged widely from acquiring technical knowledge, client relation skills, research planning to tactical networking across the organisation.

CPD for me is fluid and less-defined, evolving: it's shaped by the individual. My frame of reference is internalised [Educator]

For practitioners CPD relies on individual agency as there is no legal imperative to undertake CPD practice (Fenwick et al. 2012). Two-thirds of HR educators regarded personal choices in learning as critical to professional autonomy. In contrast, one third of respondents were troubled by the abstract nature of development:

CPD is very relevant but problematic to know what to do in terms of professional development.

What are you going to do in practice? [Educator]

Practitioners' ambivalence resonates with Boud and Hager's (2012) observation that CPD interweaves education and workplace practice. For instance, several felt that spontaneous peer discussions, reading and ongoing reflections fell between theory and practice and could not satisfy institutional expectations. This is at odds with Eraut's appeal to value informal learning in the workplace (2004), and a few educators specifically voiced concerns that audit measures of learning narrowed wider conceptions of professional education (Mackay 2015). Organisational demands for evidence of HR development are thus problematic, when different conceptualisations of professional learning (Roessger 2013) are implicit in performance contracts.

\section{Developing an HR professional identity}

At least one third of participants voiced a belief in the importance of the HR job role:

I think in HR terms, I mean we're dealing with people's lives and we're dealing with a very important asset for an organisation, in the environment in which we're operating, you do need to be able to prove, or show, or demonstrate continuous development. [Educator] 
The assertion of HR's value and role impact on employee livelihoods underpins a professional identity orientation (Evans 2008; Evetts 2003). There was substantial agreement that continuous development is essential to professionalism (item 1), which supports Freidson's (2001) research on the significance of ideal behaviour standards in professional identity. Similarly, four fifths of interviewees spoke of commitment to professional values as a practice responsibility. Two-thirds of participants strongly agreed on the need for a continuous learning mindset; but only a small majority felt practitioners are naturally committed to CPD (item 5). This is not to say that professional development can be takenfor-granted among working practitioners as a fifth of survey respondents disputed any natural commitment to learning. The majority of HR educators regarded professional development as entwined with academic expectations of scholarship. More than half the respondents articulated development associated with identity:

CPD is fundamental to my identity; it's part of me...what I am, and what I do is continually develop. I see it as a natural part of being in the HR function; you know we say it's integral, an essential part of the job. [Educator]

The need to signal growing competence in the face of global critics may, to some extent, invigorate these espoused commitments to ongoing development. Interestingly, several practitioners talked of a love of learning which suggests a partial assimilation of the image of human resources as professional development guardians (Holden 2012; Farndale et al. 2010). Several respondents traced this view of CPD to industry conditioning; a normative view of CPD embedded in practice. Two thirds of respondents voiced a responsibility to strive to be: 'more professional, more competent' which confirms efforts to strengthen professional credibility. Edwards and Nicoll $(2006,124)$ suggest that in specific situations 'professional development becomes a form of identity work'. The data illustrate educators and practitioners declaring commitment to professional service values:

it's an important part of being professional that you keep on top of things and don't stagnate. I consider CPD to be really my professional duty being up-to-date, not wanting to be caught out; and it's a mark of professional pride...I don't respect those who are only here for the beer [Educator]

These findings add empirical evidence from a specific occupational group to Friedman and Phillips' (2004) research that learning is a vital element of professionalism. But two educators were sceptical of the term 'professional' as an alluring image which employs scholarship practice to impose a managerialist ideology (Becher 1999; Kolsaker 2008). Educators' resistance to organisational control chimes with Crawford's studies (2008) where managers exploited work culture appeals to professional values. In brief, continuing development enforced as a professional value may encourage organisations to impose a selfregulating approach to employee improvement that fits institutional priorities.

\section{Motivation for professional development}

The data revealed a desire for social affiliation and peer respect which motivates continuing development. How an individual is perceived by the professional community shapes adopted behaviour and strongly influences identity formation (Haslam et al. 2000), as one reflects: 
That really matters that I feel respected by others, they know that I'm current and have my finger on the pulse; otherwise it's easy to get side-lined. And this is a small community in HR, so it does go around, you know, your reputation and whether to use that person, or avoid him...that makes a huge difference to me. [Educator]

This self-reference to the collective identity corresponds with Wenger and Snyder's (2000) research on the social interdependencies of practice learning. Two thirds of interviewees and survey respondents felt peer pressure affected individual behaviour. One articulated the effort to become a workplace role model:

I now see myself as an HR professional and have learnt how important it is to be aware of how others perceive us in our role. It matters that people think you are a professional. [Practitioner]

Interestingly, respondents emphasised a personal commitment to increasing expertise but suspected peers were less active in living up to professional standards. If a dominant social group judges CPD to be a professional value, then members may exert social power (Billett 2008) which influences a collective attitude to learning development. Jawitz's assertion (2009) of identity frame switching was evident in the interplay of individual agency and social group expectations of professionalism. Organisational situations influence the motivation to be perceived as more effective in the role:

I am aware of a natural need within me to be liked, a need that contrasts with the human resources role. As part of the job I do involves telling people information that they may not want to hear, including news of dismissals. I find this aspect of the HR role particularly difficult as I know that people always shoot the messenger, and their thoughts of me will be negatively influenced. So, in order to progress, I must continue to develop professionally. [Practitioner]

This psychological adjustment expresses professional aspirations to exhibit characteristics of trust within the work culture. The majority, four fifths of HR specialists, considered motivation for CPD an internal frame of reference; a drive for self-achievement, personal pride in meaningful work and a narrative of expanding capability: 'it gives me a momentum, a sense of moving forward' [Practitioner]. For the majority CPD contributed to self-esteem, growing confidence and competence that confer credibility in the job. This complements European research on knowledge-intensive workers where the intrinsic motivation of professional education, elevated status in the community and interesting work supported a positive work identity (Alvesson 2010). Nonetheless, one fifth asserted there was no extrinsic reward or recognition for professional development remarking: 'CPD has the air of a bit of an optional extra' [Educator].

\section{Discussion}

To address the questions that underpin this study, findings suggest that practitioners perceive professional development as a dynamic, evolving process open to individual interpretation. Moreover, expanding specialised knowledge competence shapes a coherent narrative of progress. Given the increasing demand internationally for HR practitioners with strategic capability to add business value; this growth in expertise is highly relevant to practice application. Hence, ongoing practitioner development strengthens a sense of professional identity. 


\section{Professional identity formation}

For HR educators continuous learning is integral to scholarship which resonates with Kolsaker's academic lens (2008), and for HR practitioners' fluid definitions of development (Roessger 2013) knit together educational learning and work practice. Accordingly, professional development as a malleable concept facilitates identity construction. This supports Cranton's (2011) assertion that learning development becomes a form of implicit self-identity in relation to work. Practitioners adopt responsibility for knowledge currency, for example, the impact of employment legislation changes on a multicultural workforce signals commitment to improving professional expertise which entwines with legitimacy (Billett 2008). In an international context of public detractors, specialists may accentuate the HR function's responsibilities to build collegial relations across the organisation. The psychological investment in meaningful work may partly explain the importance attributed to professional learning: 'I want to feel proud to work in HR'. An earnest belief in 'being professional' confirms Mulvey's $(2013,275)$ observation that: 'Committing to CPD may be a professional body requirement, but embracing CPD as a challenge for personal growth is an individual choice'. Data reveals that application of sophisticated capabilities unifies a sense of self in practice.

\section{Advancing respect for the human resources field}

To recap, the internationalisation of labour markets and competition for talent globally place demands on the HR function to operate more strategically within these business trends (Farndale et al. 2010). Yet the complex dimensions of HR responsibilities, which span organisational boundaries, blur understandings of specialised knowledge (Sheehan and De Cieri 2012). Human resources has inherent role contradictions; namely, championing employee concerns, coordinating management processes and also implementing organisational strategy. The multiple interests of stakeholders, managers and employees may clash with HR required to resolve issues of conflict. This complex balancing of organisational expectations has led critics in Australia, Europe and the USA to disparage the resulting fragmentation; dismissing human resources as a semi-profession which lacks legitimacy (Hammond 2005; Kearns 2009).

Key findings indicate practitioners respond proactively to these challenges and aim: 'to raise the profile of HR in my company by making good recruitment decisions [...] that demonstrate that HR does add value to the business.' This practitioner strives to counter line managers' objections to cost and evidence a specific contribution to the business. Industry and academic critics may thus, inadvertently, rally practitioners to greater determination in advancing professionalisation of the field. Collectively, there was marked comparability between educators and practitioners on the clear rationale for development commitment. This practitioner data resonates with Farndale et al.'s (2010) overview of the worldwide challenges for effective corporate HR. The sample group collectively see continuing development as an important occupational endeavour to win respect.

This suggests the wider HR community provides a disciplinary solidarity (Trede et al. 2012) for perceived underdogs in a subordinate organisational position (Gold et al. 2013). Another interpretation is that those drawn to work in human resources gradually self-define 
behaviour through the lens of the practice community (Haslam et al. 2000; Pratt et al. 2006). This study offers a preliminary collective voice of HR specialists becoming standard-bearers for the importance of learning development to secure professional legitimacy. This implies that HR specialists and personnel associations internationally need to showcase the growth, ongoing development and critical application of such professional education in context.

\section{Further Research}

This study prompts several avenues for future research: How do other aspiring professions regard continuing development? What are the specific claims of professionalisation in aspiring to professional status? For example, coaches are seen as a sub-group with peripheral status in the professional literature yet industry practice embraces coaching as an innovative and contemporary management intervention (Gray 2010). How do well-established professions theorise professional learning? To what extent does compulsory CPD constrain understandings of the scope of professional development? By extending further studies across disciplines, researchers can compare the significance of professional development for newer professions in relation to traditional professions.

\section{Conclusion}

To conclude, this study explored how practitioners make sense of professional development to navigate a sceptical environment. Findings reveal practitioners engage in competence development to alter pejorative views of the HR function and secure a positive thread of improvement continuity, which integrates a coherent professional identity. Research on continuing professional development is limited; this study adds to the international literature in providing specific evidence of an occupational group linking development currency to a claim for professional respect. This study differs from the practitioner literature (Hammond 2005; Kearns 2009) that assumes a decline in the HR function's morale and introspection in a hostile environment. Consequently, the new contribution from this study is the importance practitioners and educators place on professional learning as a unifying construction of a capable self that strengthens claims to legitimacy.

The study's specific anchoring in human resources acknowledges the organisational settings, issues and social pressures that influence working identity (Evetts 2003; Pratt et al. 2006). Consequently, situated practice opens up new meanings of professional development and, in so doing, responds to specific calls for further research in CPD (Friedman and Afitska 2009; Roessger 2013). The study complements existing international literature on the threatened status of the HR function (Sheehan and De Cieri 2012; Farndale et al. 2010) and the recent demands for professionalisation in the field to respond to the challenges of global mobility, competitive talent management and diverse staffing needs. This UK study has wider implications for the international HR community in the way we conceive of continuing professional development to secure a positive self-meaning of evolving competence that rises above critics to bolster identity.

First, the implication for CPD providers, including professional bodies, educators, and managers is to widen knowledge of multicultural practices and processes to meet global business skill shortages and retain talent. Moreover, the research findings point to a 
continuing need for better articulation of people management skills applied to practice. Practitioners need to strive for visible impact when balancing employee interests and organisational priorities. To this end, providers of CPD can help practitioners improve selfawareness and role clarity in relation to the workforce, business and stakeholders.

Second, this research interlinks the notion of professional learning with identity formation; cumulative professional growth meaningfully connects the disparate elements of the HR role to form a coherent identity. Kennedy (2014) argues the theoretical analysis of continuing development is under-represented in the literature; so this research offers a theorised framing of building competence that integrates a sense of self. This study reveals a distinctive discourse of a group, depicted as organisational guardians, who use skill and knowledge currency to signal professional credibility. Accordingly, the identity of these practitioners is defined epistemologically by the occupational understandings of professionalism, as opposed to external imposition of regulatory standards.

Finally, practitioners are keenly motivated to reduce industry scepticism about their knowledge competence. As a result, practitioners take greater ownership of professional learning, which has implications for educators in honing conscious skill development to increase performance impact. Practitioners advancing organisational expertise can thus elevate the field of human resources to a more equal power relationship with other managers, employees and business stakeholders; from marginalised underdog towards 'one to watch'. This robust approach to constant improvement has implications for advancing professionalisation in newer fields, such as coaching, and provides a pathway for other occupational groups aspiring to professional respect.

\section{References}

Alvesson, M. 2010. Self-doubters, strugglers, storytellers, surfers and others: Images of self-identities in organization studies. Human Relations 63, no. 2: 193-216.

Becher, T. 1999. Quality in the professions. Studies in Higher Education 24, no. 2: 225-235.

Billett, S. 2008. Learning throughout working life: a relational interdependence between personal and social agency, British Journal of Educational Studies 56, no.1: 39-58.

Boud, D., and P. Hager. 2012. Re-thinking continuing professional development through changing metaphors and location in professional practices, Studies in Continuing Education 34, no. 1: 17-30.

Cervero, R. 2001. Continuing professional education in transition, 1981-2000. International Journal of Lifelong Education 20, no. 1-2:16-30.

Chartered Institute of Personnel and Development [CIPD] 2012 Code of Professional Conduct www.cipd.co.uk

Cranton, P. 2011. A transformative perspective on the scholarship of teaching and learning. Higher

Education Research and Development 30, no.1: 75-86.

Crawford, K. 2008. Continuing professional development in higher education: the academic

perspective. International Journal for Academic Development 13, no. 2: 141-146.

Cunliffe, A. 2010. Crafting Qualitative Research: Morgan and Smircich 30 Years On, Organizational Research Methods 14, no. 4: 647-673. doi: 10.1177/1094428110373658.

Edwards, R. and Nicoll, K. 2006. Expertise, competence and reflection in the rhetoric of professional development. British Educational Research Journal 32, no. 1: 115-131.

Eraut, M. 2004. Informal learning in the workplace, Studies in Continuing Education 26, no. 2: 247273.

Evans, L. 2008. Professionalism, professionality and the development of education professionals. British Journal of Educational Studies 56, no. 1: 20-38. 
Evetts, J. 2003. The sociological analysis of professionalism: Occupational change in the modern world. International Sociology 18, no. 2: 395-415.

Farndale, E. and C. Brewster. 2005. In search of legitimacy: personnel management associations worldwide. Human Resource Management Journal 15, no. 3: 33-48.

Farndale, E., Scullion H. and Sallow, P. 2010. The role of the corporate HR function in global talent management, Journal of World Business 45, no.2: 161-168 doi:10.1016/j.jwb.2009.09.012

Fenwick, T. 2008. Understanding relations of individual-collective learning in work: A review of research. Management Learning 39, no. 3: 227-243.

Fenwick, T., Nerland, M. and Jensen, K. 2012. Sociomaterial approaches to conceptualizing professional learning and practice, Journal of Education and Work 25, no.1: 1-13.

Freidson, E. 2001. Professionalism, The Third Logic. Cambridge: Polity Press.

Friedman, A. and M. Phillips. 2004. Continuing professional development: Developing a vision, Journal of Education and Work 17, no.3: 361-376.

Friedman, A. and N. Afitska. 2009. Extent of CPD: The lifelong learning of millions. Bristol: Professional Associations Research Network.

Gold, J., R. Holden, P. Iles, J. Stewart and J. Beardwell. 2013. Human Resource Development, Theory and Practice. $2^{\text {nd }}$ ed. Basingstoke: Palgrave Macmillan.

Gray, D. 2010. Journeys towards the professionalization of coaching: Dilemmas, dialogues and decisions along the global pathway, Coaching: An International Journal of Theory, Research and Practice 4, no. 1:4-19.

Haslam, S., C. Powell and J. Turner. 2000. Social identity, self-categorization, and work motivation: Rethinking the contribution of the group to positive and sustainable organizational outcomes. Applied Psychology: An International Review 49, no. 3: 319-339.

Hesse-Biber, S. 2010. Qualitative approaches to mixed methods practice. Qualitative Inquiry 16, no. 6: 455-468.

Holden, R. 2012. The relevance and impact of reflective learning research. Paper presented at the University Forum for Human Resource Development Conference UFHRD 22 October, University of Portsmouth.

Jawitz, J. 2009. Academic identities and communities of practice in a professional discipline.

Teaching in Higher Education 14, no. 3: 241-251.

Kearns, P. 2009 [December-January] HR's transformation through the Noughties, Personnel Today www.personneltoday.com.

Kennedy, A. 2014. Understanding continuing professional development: the need for theory to impact on policy and practice, Professional Development in Education 40, no. 5: 688-697.

Kolsaker, A. 2008. Academic professionalism in the managerialist era: a study of English universities. Studies in Higher Education 33, no. 5: 513-525.

Mackay M. and A. Tymon. 2013. Working with uncertainty in teaching critical reflection, Teaching in Higher Education 18, no. 6: 643-655. doi:10.1080/13562517.2013.774355

Mackay, M. 2015. Professional development seen as employment capital, Professional Development in Education. doi: 10.1080/19415257.2015.1010015.

Mulvey, R. 2013. How to be a good professional: existentialist continuing professional development (CPD), British Journal of Guidance and Counselling 41, no. 3: 267-276.

Nixon, J. 2001. Not without dust and heat: The moral bases of the 'new' academic professionalism.

British Journal of Educational Studies 49, no. 2: 173-186.

Organisation for Economic Co-operation and Development. OECD 2010. Recognising Non-formal and Informal Learning: Outcomes, Policies and Practices. ww.oecd.org/education/

Pratt, M., K. Rockmann and J. Kaufmann. 2006. Constructing professional identity: The role of work and identity learning cycles in the customization of identity among medical residents. Academy of Management Journal 49: 235-262.

Roessger, K. 2013. But does it work? Reflective activities, learning outcomes and instrumental learning in continuing professional development. Journal of Education and Work 28, no.1 83- 105. Rothwell, A. 2005. How HR professionals rate 'continuing professional development'. Human Resource Management Journal 15, no. 3: 18-32.

Saunders, M., P. Lewis and A. Thornhill. 2011. Research methods for business students. $6^{\text {th }}$ ed. Harlow: Financial Times Prentice Hall. 
Sheehan, C. and De Cieri, H. 2012. Charting the strategic trajectory of the Australian HR professional. Asia Pacific Journal of Human Resources 50, 151-168.

Society of Human Resource Management SHRM 2007. HR and business education: Building value for competitive advantage. SHRM Research Quarterly 2: 1-10.

Stiglitz, J. 1999. Knowledge as a global public good. Global Public Goods: International Cooperation in the $21^{\text {st }}$ Century. The United Nations Development Programme. New York: Oxford University Press.

Tracy, S. 2010. Qualitative quality: Eight "big tent" criteria for excellent qualitative research. Qualitative Inquiry 16, 10: 837-851.

Trede, F., R. Macklin, and D. Bridges. 2012. Professional identity development: a review of the higher education literature, Studies in Higher Education 37, no.3: 364-384.

Ulrich, D. and W. Brockbank. 2005. The HR value proposition. Boston, MA: Harvard

Business School Press.

Volles, N. 2014. Lifelong learning in the EU: changing conceptualizations, actors and policies, Studies in Higher Education, DOI: 10.1080/03075079.2014.927852

Wenger, E. and W. Snyder. 2000. Communities of practice: The organizational frontier. Harvard Business Review 78, no. 1: 139-145.

Weston, C., T. Gandell, J. Beauchamp, L. McAlpine, C. Wiseman and C. Beauchamp. 2001. Analyzing interview data: The development and evolution of a coding system. Qualitative Sociology 24, no. 3: 381-400. 